\title{
PVdF-HFP-Based Gel Polymer Electrolyte with Semi-Interpenetrating Networks For Dendrite-Free Lithium Metal Battery
}

\author{
Lu Liu' ${ }^{1}$ Xiaodong Wang ${ }^{1} \cdot$ Chenhui Yang ${ }^{1} \cdot$ Peng Han ${ }^{1} \cdot$ Lei Zhang $^{2} \cdot$ Li Gao $^{3} \cdot$ Zirui Wu$^{1} \cdot$ Bingxin Liu $^{3} \cdot$ Ruiping Liu $^{1}$
}

Received: 23 July 2020 / Revised: 26 August 2020 / Accepted: 2 September 2020 / Published online: 16 October 2020

(C) The Chinese Society for Metals (CSM) and Springer-Verlag GmbH Germany, part of Springer Nature 2020

\begin{abstract}
The safety issues and lower energy density of the lithium metal batteries are the two main challenges that hinder their applications in the fields of electric vehicles and portable devices. In this work, the semi-interpenetrated polyvinylidene fluoride-hexafluoropropylene (PVdF-HFP)-based gel polymer electrolyte was synthesized through UV-curing method by employing the ethoxylated trimethylolpropane triacrylate (ETPTA) monomer. The semi-interpenetrating networks formed by polymerization of ETPTA and the high liquid absorption rate of the PVdF-HFP impart the as-prepared electrolyte with a high room temperature ionic conductivity of $3.17 \times 10^{-3} \mathrm{~s} \mathrm{~cm}^{-1}$ and a high mechanical strength of $3.46 \mathrm{MPa}$. $\mathrm{LiFePO}_{4}$ was selected as cathode materials, and the active material loading of the cathode is about $4.2 \mathrm{mg} \mathrm{cm}^{-2}$. The electrolyte shows superior long-term cycling properties $\left(127 \mathrm{mAh} \mathrm{g}^{-1}\right.$ after 200 cycles at $\left.0.5 \mathrm{C}\right)$, excellent rate performance $\left(113 \mathrm{mAh} \mathrm{g}^{-1}\right.$ at $1 \mathrm{C}, 80 \mathrm{mAh} \mathrm{g}^{-1}$ at $2 \mathrm{C}$, and the discharge capacity of $135 \mathrm{mAh} \mathrm{g}^{-1}$ can be restored when the rate goes back to $0.1 \mathrm{C}$ ) as well as good ability to inhibit the growth of lithium dendrite (about $150 \mathrm{~h}$ ). The facile synthesis strategy and great electrochemical performance of the electrolyte make it a potential candidate for lithium metal batteries.
\end{abstract}

Keywords Gel polymer electrolyte $\cdot \mathrm{PVdF}-\mathrm{HFP} \cdot \mathrm{UV}$-curing $\cdot$ Lithium dendrite

\section{Introduction}

Lithium metal batteries (LMBs) with high specific energy density are attracting more and more attention due to the rapid development of the electric vehicles (EVs), hybrid electric vehicles (HEVs) and portable devices [1-8]. However, the safety issues caused by the growth of lithium dendrites and the utilization of the organic liquid electrolyte hinder its commercialization [9-11]. Compared with

Available online at https://link.springer.com/journal/40195.

Lei Zhang

lzhang14@alaska.edu

Ruiping Liu

201402@cumtb.edu.cn

1 Department of Materials Science and Engineering, China University of Mining and Technology (Beijing), Beijing 100083, China

2 Department of Mechanical Engineering, University of Alaska Fairbanks, Fairbanks, AK 99775-5905, USA

3 School of Mechanical Engineering, Qinghai University, Xining 810016, China the liquid electrolyte, the solid electrolyte exhibits higher energy density and high safety, and especially the gel polymer electrolyte can not only achieve high ion conductivity, decrease the interfacial charge transfer resistance between the electrode and electrolyte, but also prevent the growth of the lithium dendrites through regulating the deposition of lithium metal [12-16]. Thus, it is highly desired to develop gel polymer electrolytes with high electrochemical properties to match the requirement of the lithium metal battery.

Numerous research work has been done to improve the ionic conductivity and mechanical strength of the polymer electrolytes. Most of the work was focused on the modification of polyethylene oxide (PEO) either by doping with inorganic nanoparticles or copolymerization with other polymers to inhibit the crystallization of the PEO, and finally increase the room temperature ionic conductivity of PEO [17-21]. However, the high crystallinity of the PEO at room temperature (i.e., low ionic conductivity) is still a main challenge in the commercialization of the PEO-based polymer electrolyte. Moreover, conventional PEO matrix electrolytes cannot match with high voltage during charging/discharging process, which will limit its application in the utilization of the ternary cathode material (NCM) [22, 23]. 
Polyvinylidene fluoride-hexafluoropropylene (PVdFHFP), as a matrix of polymer electrolyte, can not only withstand high voltage, but also possess good liquid absorption rate and good mechanical strength, which will impart the cell with higher energy density, faster reaction kinetics and high safety [24-26]. In this work, we introduce a semiinterpenetrated PVdF-HFP-based polymer electrolyte synthesized by UV-curing method. PVdF-HFP was used as a matrix to introduce macromolecules, and the monomeric ethoxylated trimethylolpropane triacrylate (ETPTA) initiated polymerization under ultraviolet light to form a network structure, which together formed a semi-interpenetrated polymer electrolyte. The introduction of the network will benefit for the improvement in the mechanical strength of polymer electrolyte and the enhancement of the performance of lithium metal batteries.

\section{Experimental}

\subsection{Synthesis of the Polymer Electrolyte}

The PVdF-HFP-based semi-interpenetrated polymer membranes were synthesized by UV-curing method. Typically, the transparent solution was obtained by stirring $2 \mathrm{~g}$ of PVdF-HFP and $30 \mathrm{~mL}$ of acetone for $2 \mathrm{~h}$, followed by the addition of $1 \mathrm{~g}$ of ETPTA monomer and $0.01 \mathrm{~g}$ of the photoinitiator 2-hydroxy-2-methyl-propiophenone (HMPP) with a weight fraction of $1.0 \mathrm{wt} \%$. After stirring the homogeneous precursor solution for $2 \mathrm{~h}$ at ambient temperature, poured and coated onto the glass plate, the glass plate was subjected to UV-curing process conducted on a Hg UV-lamp (Lichtzen) for $60 \mathrm{~s}$ with an irradiation peak intensity of $2000 \mathrm{mw} \mathrm{cm}^{-2}$. Then the electrolyte was peeled off, washed three times with methanol solvent to remove remained monomers, crosslinkers and excess photoinitiators and finally vacuum dried for $12 \mathrm{~h}$ to obtain the cleaned polymer membranes after removing the solvents. The gel polymer electrolyte was prepared by soaking the polymer membranes in the liquid electrolyte $\left(1 \mathrm{M} \mathrm{LiPF}_{6}\right.$ in $\left.\mathrm{EC} / \mathrm{PC} / \mathrm{EMC}=1 / 1 / 1(\mathrm{v} / \mathrm{v} / \mathrm{v})\right)$ for $12 \mathrm{~h}$ successively.

\subsection{Characterization Method}

The field emission scanning electron microscope (FE-SEM, Zeiss Supra 40VP) was used to observe the microstructures of the electrolytes. The Fourier transform infrared spectrometer (FTIR, Nicolet Magna 750 IR FTIR) was used to analyze the crosslinking degree of the precursor before and after UV-curing. The crystallinity of the electrolytes was analyzed by X-ray diffraction (XRD, Bruker D8, Germany). The thermal stability of the electrolytes was determined by using thermogravimetry (TG, Seiko TG/DTA 7300, Japan).
The mechanical strength of the electrolytes was evaluated by dynamic mechanical force analyzer (NETZSCH, DMA Q800) and visualization experiment of artificial stretching.

\subsection{Electrochemical Measurement}

The lithium ionic conductivity of the electrolytes was measured by using two electrodes method, in which the electrolytes were fixed between two stainless steel electrodes with a surface area of $1.76 \mathrm{~cm}^{2}$, and the measurement was conducted on a SP-300 potentiostat/galvanostat frequency response analyzer instrument (FRA, Bio-Logic, France) at the frequency range of $1 \mathrm{~Hz}$ to $100 \mathrm{kHz}$ at the open-circuit voltage. The 2032-type coin cell was selected to evaluate the electrochemical performance, which was assembled in an argon-filled glove box with the oxygen and water content lower than $0.1 \mathrm{ppm}$. The neat lithium foil and $\mathrm{LiFePO}_{4}$ (the weight ratio of active materials: PVDF: Super-P is $8: 1: 1$ ) was selected as the anode and cathode separately, and the active material loading of cathode is around $4.2 \mathrm{mg} \mathrm{cm}^{-2}$. The electrochemical properties of the cells with the gel polymer electrolytes were evaluated by cycling on a Land CT2001 A battery testing system at different rates. The electrochemical impedance spectroscopy (EIS) and cyclic voltammetry (CV) measurements were conducted on an electrochemical workstation (CHI660E, CH Instrument), and the scan rate is $0.1 \mathrm{mV} \mathrm{s}^{-1}$ from $0.01 \mathrm{~Hz}$ to $100 \mathrm{kHz}$. The ability to inhibit the growth of lithium dendrite of the electrolytes was evaluated by cycling the symmetrical cell (Li/electrolyte/ $\mathrm{Li}, 2032$-type coin) at $0.5 \mathrm{~mA} \mathrm{~cm}^{-2}$.

\section{Results and Discussion}

Figure 1 is the schematic diagram showing the preparation process of the PVdF-HFP-based polymer electrolyte. The PVdF-HFP is uniformly mixed with the macromolecular ethoxylated trimethylolpropane triacrylate (ETPTA) monomer by physical mixing, and the polymerization was initiated by ultraviolet light in the presence of a solvent. A polymer membrane with controlled thickness and uniform surface could be obtained after tape-coating. The PVdFHFP-based semi-interpenetrated gel polymer electrolyte was obtained after washing, drying and immersing in the liquid electrolyte.

In order to demonstrate the presence of a polymer network formed by ETPTA monomers, PVdF-HFP in the polymer membrane was etched by acetone. In Fig. 2, the network structure of the electrolyte still exists after etching, indicating the occurrence of UV-curing polymerization. Figure 3 displays the surface morphology of PVdF-HFPbased semi-interpenetrating polymer network electrolytes. The surface of the electrolyte membrane is very uniform, 


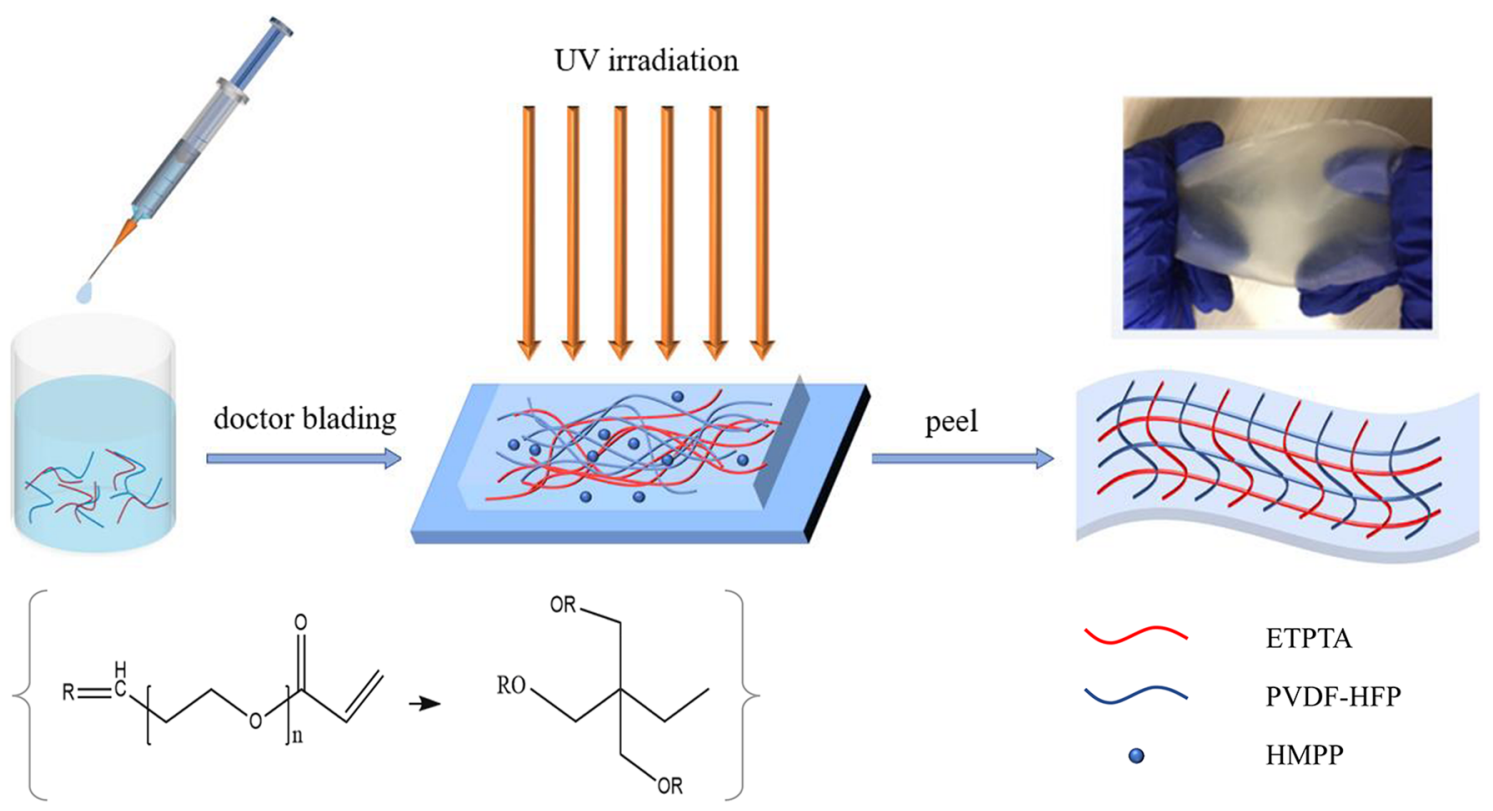

Fig. 1 Schematic diagram showing the synthesis procedure of the electrolyte
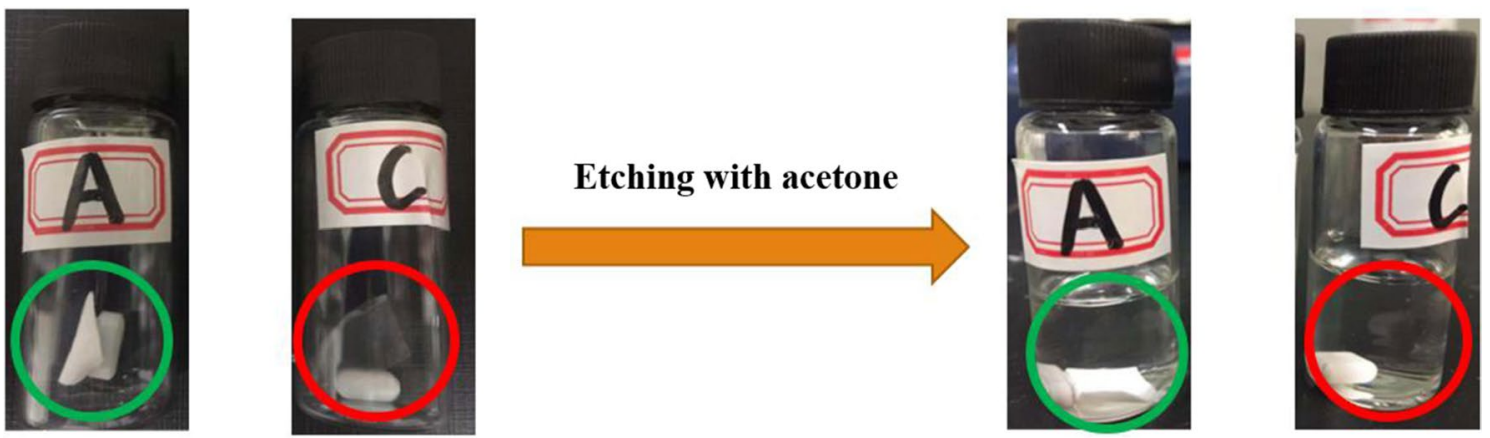

Fig. 2 Schematic diagram of the etching process of the as-prepared electrolyte with acetone as a solvent. A is the electrolyte membrane obtained after UV-curing, and $\mathrm{C}$ is the pure PVdF-HFP membrane

indicating that the coating and curing process is very effective (Fig. 3a). The surface network structure of the PVdFHFP-based gel polymer network electrolyte can be clearly seen in Fig. 3b. The layered structure and some voids and pores can be observed, wherein the layered structure represents the UV-cured ETPTA macromolecular skeleton, and the formation of voids or pores is mainly attributed to the evaporation of acetone solvent. The existence of the voids or pores will ensure better liquid absorption performance of the electrolyte by providing space for the liquid electrolyte infiltration. Further observation shows that the network structure and uniform gaps are intersected with each other (Fig. 3c), and the thickness of the electrolyte membrane is about $120 \mu \mathrm{m}$ (Fig. 3d).

Figure 4a shows the infrared absorption spectra of the PVdF-HFP-based electrolyte. It can be clearly observed that two FTIR peaks located at $1618 \mathrm{~cm}^{-1}$ and $1638 \mathrm{~cm}^{-1}$ before UV irradiation, which can be ascribed to the acrylic $\mathrm{C}=\mathrm{C}$ bonds of ETPTA monomers [27, 28]. After UV irradiation, the two peaks disappeared, confirming that the ETPTA monomer was successfully polymerized in the precursor mixture. XRD results further confirmed the depressed crystallization of PVdF-HFP by forming the semi-interpenetrating network (Fig. 4b). The XRD pattern of the pure PVdF-HFP electrolyte membrane is composed of three strong peaks $\left(2 \theta=19^{\circ}, 26^{\circ}\right.$ and $\left.40^{\circ}\right)$, which can be ascribed to the characteristic peaks of the crystal PVdF-HFP. After UV irradiation, the characteristic peak at $2 \theta=40^{\circ}$ disappeared, and the characteristic peaks at $2 \theta=19^{\circ}$ and $26^{\circ}$ were significantly weakened, and the overall peak shape became broad. This indicates that the ETPTA macromonomer was polymerized in PVdF-HFP. The formation of a structure similar to 

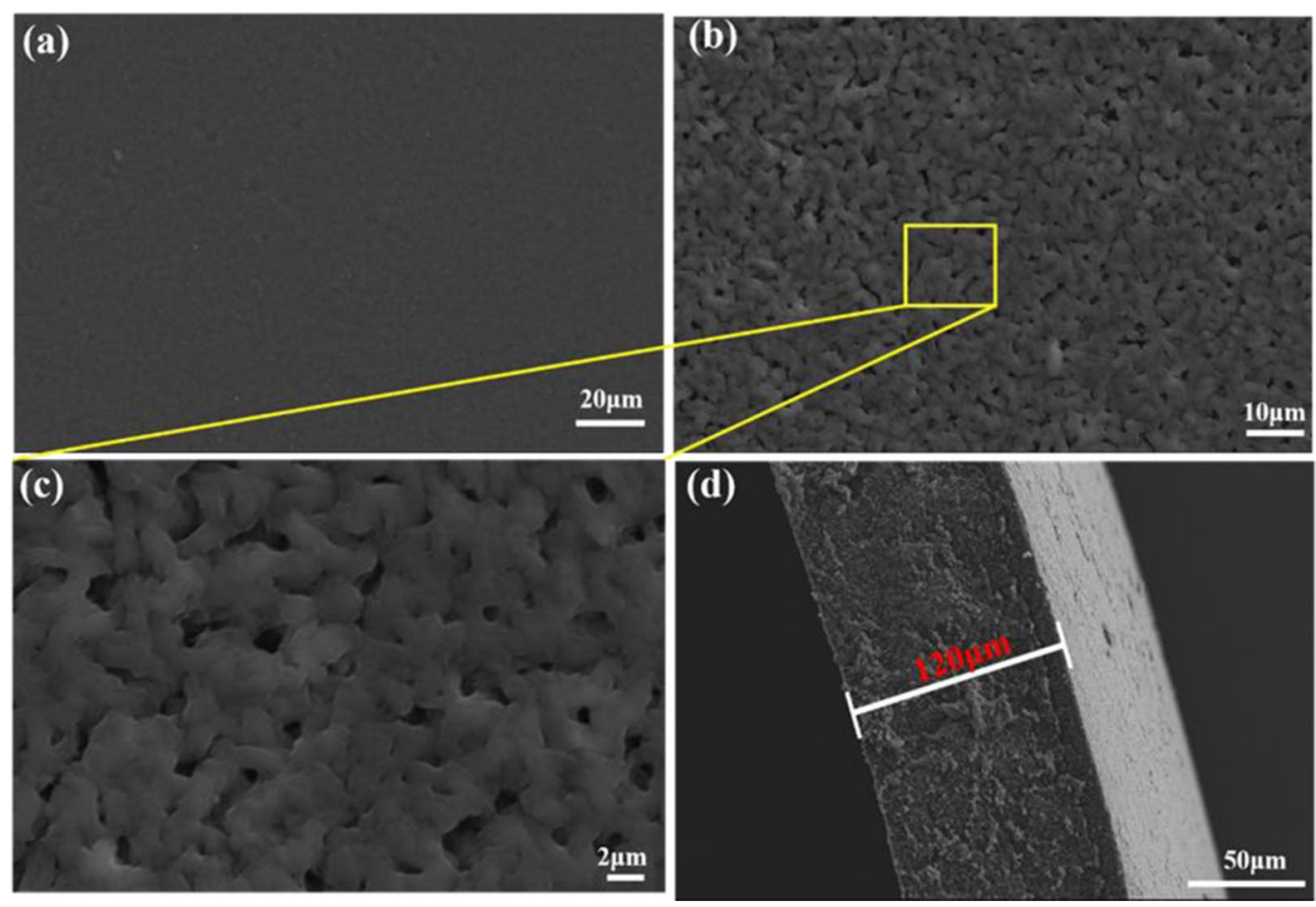

Fig. 3 SEM images of $\mathbf{a}, \mathbf{b}$ the as-prepared gel polymer electrolytes, $\mathbf{c}$ enlarged area of $\mathbf{b}, \mathbf{d}$ the cross-section image of the electrolytes

the "cage" in the electrolyte reduces the crystallinity of the PVdF-HFP, and the proportion of the amorphous portion increases, which means that the electrolyte membrane can absorb more electrolyte [29, 30]. It is beneficial to increase the liquid absorption and ionic conductivity of the electrolyte membrane, thereby obtaining higher mobility of lithium ions.

The thermal stability of the polymer electrolyte membrane was evaluated by thermogravimetric analysis (TGA) (Fig. 4c). PVdF-HFP matrix exhibited the best thermal stability of about $425{ }^{\circ} \mathrm{C}$, and the PVdF-HFP-based semiinterpenetrating polymer network electrolyte started to decompose at $350{ }^{\circ} \mathrm{C}$, which was due to the decomposition of the polymer network formed by polymerization of ETPTA macromonomer. The gel electrolytes soaked in the electrolyte began to thermally decompose at $60{ }^{\circ} \mathrm{C}$, and the gel electrolytes began to show significant weight loss between $100{ }^{\circ} \mathrm{C}$ and $150{ }^{\circ} \mathrm{C}$. It can be attributed to the decomposition of the swollen liquid electrolyte in the semi-interpenetrated network. The overall structure of the polymer remained stable between $150{ }^{\circ} \mathrm{C}$ and $350{ }^{\circ} \mathrm{C}$, and the weight loss at $350{ }^{\circ} \mathrm{C}$ and $425^{\circ} \mathrm{C}$ can be attributed to the decomposition of the polymer network formed by the macromonomer and the PVdF-HFP, respectively. Figure 4d shows the temperature-dependent ionic conductivity of the PVdF-HFP-based semi-interpenetrating polymer network electrolyte. Due to the high concentration of liquid electrolyte in the PVdF-HFP-based semi-interpenetrating polymer network electrolyte and the pore structure, the electrolyte has a high lithium ion conductivity at ambient temperature $\left(3.17 \times 10^{-3} \mathrm{~s} \mathrm{~cm}^{-1}\right)$ and $80{ }^{\circ} \mathrm{C}\left(7.01 \times 10^{-3} \mathrm{~s} \mathrm{~cm}^{-1}\right)$. It can be seen that as the temperature increases, the conductivity of the electrolyte does not increase significantly because the polymer electrolyte in the gel state itself already has a high ionic conductivity at room temperature.

Figure 5 shows the mechanical properties of the gel polymer electrolyte membranes. In general, in polymer electrolytes, ionic conductivity and mechanical strength are two contradictory properties; the higher the ionic conductivity, the lower the mechanical strength. It has been mentioned previously that the PVdF-HFP-based semi-interpenetrating polymer network electrolyte has high ionic conductivity at both ambient and high temperature. The tensile strength of the electrolyte is as high as 3.46 MPa. As shown in the inset of Fig. 5, the distance between the two red dots gradually increases during stretching, and when the distance between the red dots reaches about three times compared to the initial distance, no cracks or breakage can be observed, indicating that the polymer membrane possesses a good mechanical strength, which will impart the polymer electrolyte with better safety performance when applied to lithium ion batteries.

As shown in Fig. 6, the electrochemical performance of a Li/LFP battery assembled with PVdF-HFP-based semiinterpenetrating polymer network electrolyte membrane in gel state was tested at different rates. Figure 6a presents the cyclic voltammetry curve of a Li-LFP cell equipped with 

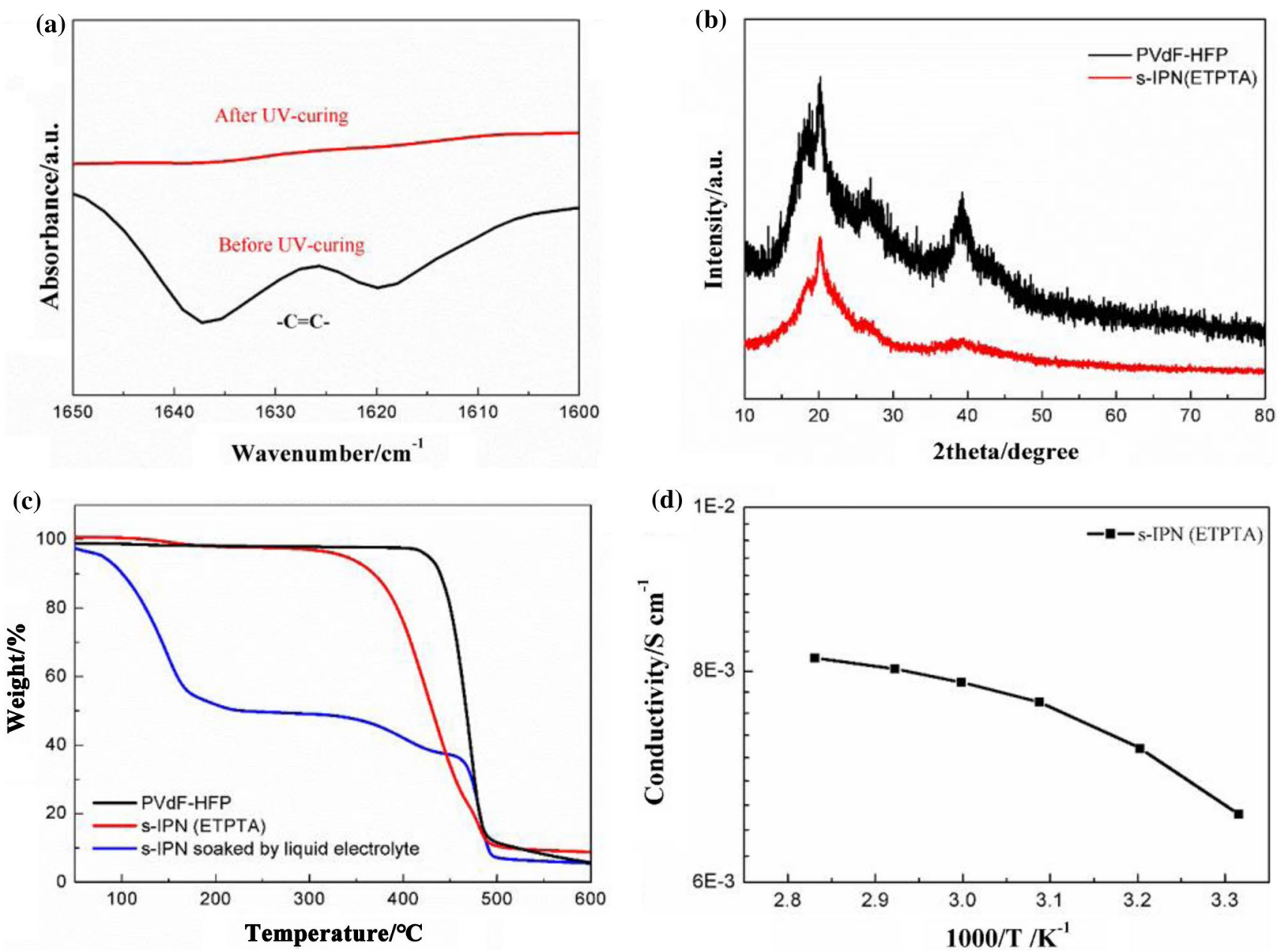

Fig. 4 a FTIR spectra of acrylic $\mathrm{C}=\mathrm{C}$ bonds $\left(1600-1650 \mathrm{~cm}^{-1}\right)$ of ETPTA (before/after UV-crosslinking) in the electrolytes, b XRD patterns of the electrolytes (before/after UV-crosslinking), c TGA curves of the PVdF-HFP-based semi-interpenetrating network polymer electrolyte (red), PVdF-HFP (black) and the PVdF-HFP-based semi-interpenetrating network polymer electrolyte soaked by liquid electrolyte (blue), $\mathbf{d}$ temperature-dependent ionic conductivities of the electrolytes

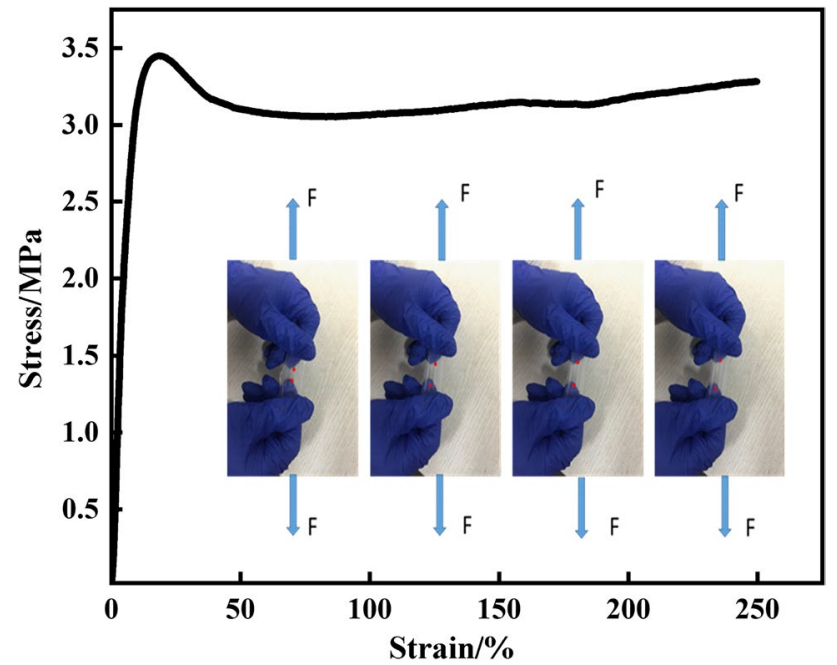

Fig. 5 Stress-strain curve of the electrolyte, the insets showing the images of the tensile stretching process of the electrolyte a PVdF-HFP-based semi-interpenetrating polymer network electrolyte with a scan speed of $0.5 \mathrm{mV} \mathrm{s}^{-1}$ at $25^{\circ} \mathrm{C}$. The symmetrical oxidation/reduction peaks at $3.0 \mathrm{~V}$ and $3.9 \mathrm{~V}$ can be seen between $2.5 \mathrm{~V}$ and $4.2 \mathrm{~V}$, which correspond to the redox reaction occurring inside the battery, and no other redox peaks can be observed, indicating that the PVdFHFP-based semi-interpenetrating polymer network electrolyte exhibits good electrochemical stability. The first three CV curves are substantially coincident, which indicates the good reversibility of the electrolyte. The first charge-discharge specific capacity was around $140 \mathrm{mAh} \mathrm{g}^{-1}$ at 0.5 $\mathrm{C}$, and the discharge specific capacity of $128 \mathrm{mAh} \mathrm{g}^{-1}$ was obtained after the 100 cycles. The relative high discharge capacity of $127 \mathrm{mAh} \mathrm{g}^{-1}$ with about $90.7 \%$ of capacity retention could be maintained after the 200 cycles, demonstrating the excellent long-term cycling performance of the electrolyte (Fig. 6b). Figure 6c shows the capacity-voltage profiles of the 1st, 100th and 200th cycles during charge/discharge 

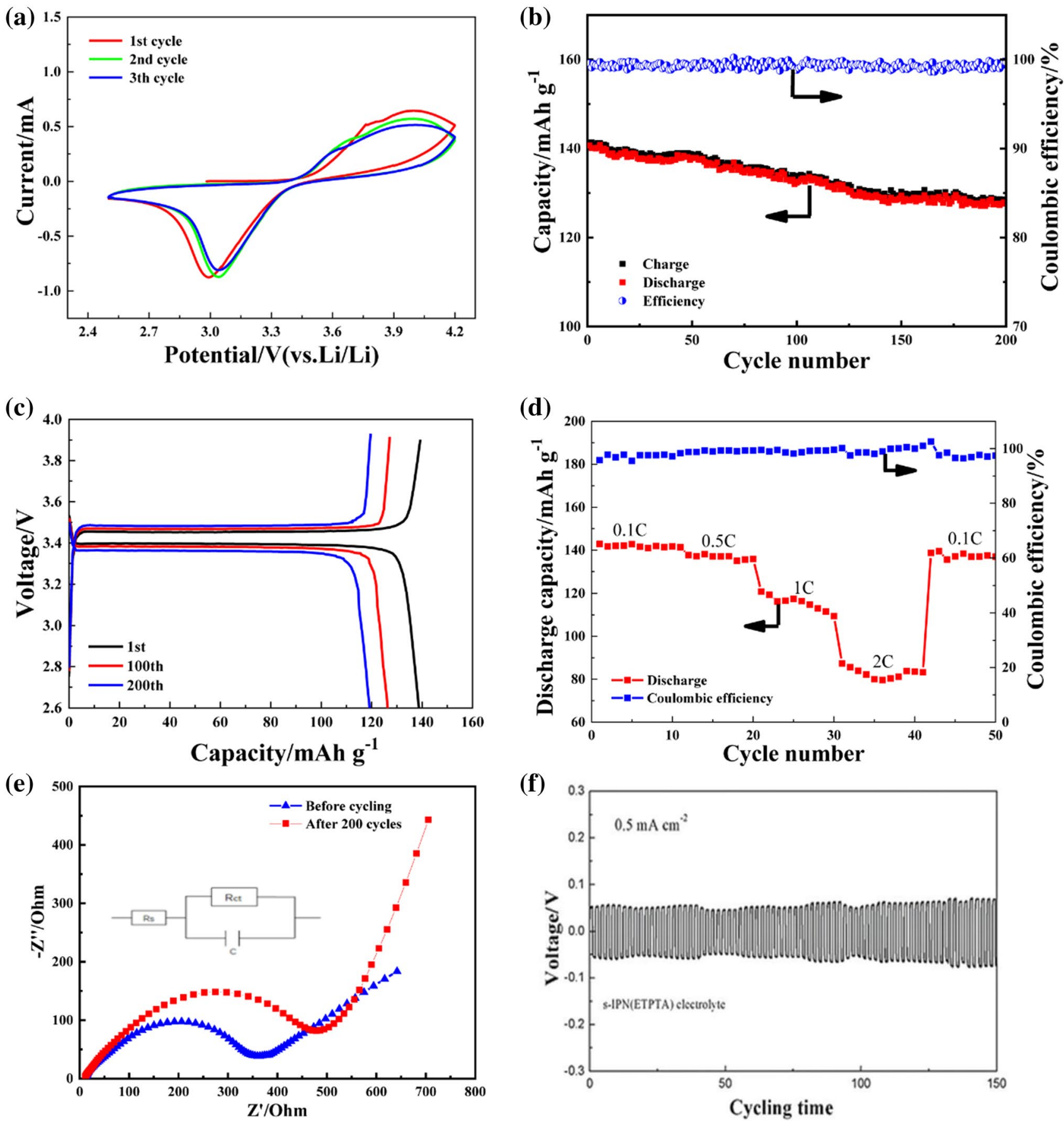

Fig. $6 \mathrm{CV}$ curves $\mathbf{a}$, cycling performance $\mathbf{b}$, voltage-capacity profiles $\mathbf{c}$ rate performance $\mathbf{d}$ of the cells with as-prepared gel polymer membranes as electrolytes, EIS spectra of the cells with the as-prepared electrolyte before and after cycling e, galvanostatic cycling tests of Li/electrolyte/Li at $0.5 \mathrm{~mA} \mathrm{~cm}^{-2} \mathbf{f}$

process at $0.5 \mathrm{C}$. The curves show a clear and stable voltage platform, indicating that the battery possesses a good output and long cycle life. It also shows that the polymer composite solid electrolyte prevents the piercing of lithium dendrites during the whole charge and discharge cycle, thus avoiding the battery internal short circuit. The specific capacity of the cell with the as-prepared gel polymer electrolyte was close to $142 \mathrm{mAh} \mathrm{g}^{-1}$ at $0.1 \mathrm{C}$, and a specific discharge capacity of about $80 \mathrm{mAh} \mathrm{g}^{-1}$ could still be obtained even after it was cycled for a long time at a high current density of 2 C. More importantly, when the current density went back to $0.1 \mathrm{C}$, the discharge capacity of $135 \mathrm{mAh} \mathrm{g}^{-1}$ could be 
restored, indicating that the electrolyte possesses good rate performance (Fig. 6d).

Figure 6e shows the impedances of the cell before and after 200 cycles. The impedance of the cell before cycling was $350 \Omega$, and the cell impedance increased to $470 \Omega$ after 200 cycles. The small impedance increase in the cell after 200 cycles further demonstrated the relatively stable interface between the electrolyte and electrode, as well as the good interfacial compatibility between the electrolyte and electrode. To investigate the ability to inhibit the growth of lithium dendrites of the electrolyte, the symmetrical LilelectrolytelLi battery was assembled and cycled at 0.5 $\mathrm{mA} \mathrm{cm}{ }^{-2}$. Figure $6 \mathrm{f}$ shows the voltage evolution curve of the cell with the increase in cycling time. It is commonly assumed that the voltage will suddenly change when the lithium dendrites grow and pierce the electrolyte [31]. After a long cycling time of $150 \mathrm{~h}$, the voltage during charge/ discharge process shows little increase, which indicates that the PVdF-HFP-based semi-interpenetrated gel electrolyte can effectively prevent the growth of the lithium dendrites during cycling and thus improve the safety and long-term cycling properties of the cell. PVdF-based materials have many advantages such as high thermal stability, good filmforming properties and high resistance to electrochemical oxidation, and also they show a significant effect on the dissociation of lithium salts and the improvement in ion migration. ETPTA is added to improve the mechanical properties, thermal stability and electric conductivity of the gel polymer electrolyte by forming a cross-linked semi-interpenetrating network. Thus, lithium dendrite growth during cycling can be suppressed by the high ionic conductivity and mechanical properties of the electrolytes.

\section{Conclusion}

In this work, a PVdF-HFP-based semi-interpenetrated gel polymer electrolyte was successfully synthesized by UVcuring method. PVdF-HFP as a matrix provides high liquid absorption and imparts high toughness and flexibility to the electrolyte membrane, while the polymerized ETPTA macromonomers can ensure the excellent mechanical strength of the electrolyte. The high ionic conductivity, high mechanical strength at room temperature and good flexibility of the gel polymer electrolyte provide a basis for preparing electrolyte membranes with various shapes for different devices. The preparation of such a semi-interpenetrated gel polymer electrolyte is easy to operate, and the as-prepared electrolyte can be one of the most promising electrolytes applied in flexible devices and wearable devices.

Acknowledgements This work was financially supported by the Natural Science Foundation of Beijing Municipal (No. L182062), the talents project of Beijing Municipal Committee Organization Department (No. 2018000021223ZK21), the Yue Qi Young Scholar Project of China University of Mining \& Technology (Beijing) (No. 2017QN17) and the Fundamental Research Funds for the Central Universities (Nos. 2020XJJD01 and 2020YJSJD01).

\section{References}

[1] P. Meduri, E. Clark, J.H. Kim, E. Dayalan, G.U. Sumanasekera, M.K. Sunkara, Nano Lett. 12, 1784 (2012)

[2] H.B. Yao, G.Y. Zheng, W.Y. Li, M.T. McDowell, Z.W. Seh, N.A. Liu, Z.D. Lu, Y. Cui, Nano Lett. 13, 3385 (2013)

[3] B.B. Wu, J. Lochala, T. Taverne, J. Xiao, Nano Energy 40, 34 (2017)

[4] C.L. Yang, X.W. Zhong, Y. Jiang, Y. Yu, Chin. Chem. Lett. 28 , $2231(2017)$

[5] Z.X. Wei, B. Ding, H. Dou, J. Gascon, X.J. Kong, Y.J. Xiong, B. Cai, R.Y. Zhang, Y. Zhou, M.C. Long, J. Miao, Y.H. Dou, D. Yuan, J.M. Ma, Chin. Chem. Lett. 30, 2110 (2019)

[6] B.L. Xu, S.H. Qi, M.M. Jin, X.Y. Cai, L.F. Lai, Z.T. Sun, X.G. Han, Z.F. Lin, H. Shao, P. Peng, Z.H. Xiang, J.E. ten Elshof, R. Tan, C. Liu, Z.X. Zhang, X.C. Duan, J.M. Ma, Chin. Chem. Lett. 30, 2053 (2019)

[7] K. Shi, C. Lai, X. Liu, Y. Wei, W. Lv, J. Wang, J. Li, C. Yan, B. Li, Q.H. Yang, F. Kang, Y.B. He, Energy Storage Mater. 17, 111 (2019)

[8] D.C. An, L. Shen, D.N. Lei, L.H. Wang, H. Ye, B.H. Li, F.Y. Kang, Y.B. He, J. Energy Chem. 31, 19 (2019)

[9] Y.X. Chen, X.Y. Dou, K. Wang, Y.S. Han, Adv. Energy Mater. 9, 1900019 (2019)

[10] X. Zhang, S. Wang, C.J. Xue, C.Z. Xin, Y.H. Lin, Y. Shen, L.L. Li, C.W. Nan, Adv. Mater. 31, 1806082 (2019)

[11] H. Wang, J. He, J. Liu, S. Qi, M. Wu, J. Wen, Y. Chen, Y. Feng, J. Ma, Adv. Funct. Mater. 29, 202002578 (2020)

[12] J.B. Goodenough, K.S. Park, J. Am. Chem. Soc. 135, 1167 (2013)

[13] A.L. Ahmad, U.R. Farooqui, N.A. Hamid, RSC Adv. 8, 25725 (2018)

[14] D.Z. Yang, L. He, Y. Liu, W.Q. Yan, S.S. Liang, Y.S. Zhu, L.J. Fu, Y.H. Chen, Y.P. Wu, J. Mater. Chem. A 7, 13679 (2019)

[15] D.D. Han, Z.Y. Wang, G.L. Pan, X.P. Gao, A.C.S. Appl, Mater. Interfaces 11, 18427 (2019)

[16] C.L. Yan, Rare Met. 39, 458 (2020)

[17] R.P. Liu, P. He, Z.R. Wu, F. Guo, B. Huang, Q. Wang, Z.Y. Huang, C.A. Wang, Y.T. Li, J. Electroanal. Chem. 822, 105 (2018)

[18] A. Bac, M. Ciosek, M. Bukat, M. Marczewski, H. Marczewska, W. Wieczorek, J. Power Sources 159, 405 (2006)

[19] C.W. Lin, C.L. Hung, M. Venkateswarlu, B.J. Hwang, J. Power Sources 146, 397 (2005)

[20] Y.H. Zhu, J. Cao, H. Chen, Q.P. Yu, B.H. Li, J. Mater. Chem. A 7, 6832 (2019)

[21] Z. Wan, D. Lei, W. Yang, C. Liu, K. Shi, X. Hao, L. Shen, W. Lv, B. Li, Q.H. Yang, F. Kang, Y.B. He, Adv. Funct. Mater. 29, 1805301 (2019)

[22] L. Chen, Y.T. Li, S.P. Li, L.Z. Fan, C.W. Nan, J.B. Goodenough, Nano Energy 46, 176 (2018)

[23] E.M. Masoud, A.A. El-Bellihi, W.A. Bayoumy, M.A. Mousa, J. Alloys Compd. 575, 223 (2013)

[24] M. Khalifa, A. Mahendran, S. Anandhan, Polym. Compos. 40, 1663 (2019)

[25] Y. Xia, X.L. Wang, X.H. Xia, R.C. Xu, S.Z. Zhang, J.B. Wu, Y.F. Liang, C.D. Gu, J.P. Tu, Chem. Eur. J. 23, 15203 (2017)

[26] M.Y. Zhang, M.X. Li, Z. Chang, Y.F. Wang, J. Gao, Y.S. Zhu, Y.P. Wu, W. Huang, Electrochim. Acta 245, 752 (2017) 
[27] A. Bhat, B. Smith, C.Z. Dinu, A. Guiseppi-Elie, Mater. Sci. Eng. C 98, 89 (2019)

[28] R.P. Liu, Z.R. Wu, P. He, H.Y. Fan, Z.Y. Huang, B. Huang, L. Zhang, X.S. Chang, H. Liu, C.A. Wang, Y.T. Li, J. Materiomics 5, 185 (2019)

[29] M. Falco, C. Simari, C. Ferrara, J.R. Nair, G. Meligrana, F. Bella, I. Nicotera, P. Mustarelli, M. Winter, C. Gerbaldi, Langmuir 35, $8210(2019)$
[30] J. Amici, S. Romanin, M. Alidoost, D. Versaci, C. Francia, F. Smeacetto, S. Bodoardo, J. Electroanal. Chem. 837, 103 (2019)

[31] L. Meabe, T.V. Huynh, D. Mantione, L. Porcarelli, C.M. Li, L.A. O'Dell, H. Sardon, M. Armand, M. Forsyth, D. Mecerreyes, Electrochim. Acta 302, 414 (2019) 